TP Periodica Polytechnica Chemical Engineering

60(2), pp. 136-140, 2016

DOI: $10.3311 /$ PPch.8357

Creative Commons Attribution (i)

RESEARCH ARTICLE

\section{Effect of Fiber Angel of Unidirectional Longitude Fiber on Transverse Strength of Pultruded Polyester Rod}

\author{
Babak Jouyande ${ }^{1}$, Mohammad Rahim Vaseghi ${ }^{1}$, \\ Amir Hossein Haghighi ${ }^{*}$
}

Received 26 June 2015; accepted after revision 12 October 2015

\begin{abstract}
In this research by using a new technique which is named, Rotational Pultrusion, angular entrance of uni-directional (UD) fibers directly into the process was successfully reached. E-glass/ polyester rods' samples pultruded with different fiber angles and testing them with three points bending. The test showed that with an increase in UD fiber angle, toward pultruded rod direction, finally the modulus and strength on transverse direction were increased.
\end{abstract}

\section{Keywords}

transverse strength, unidirectional longitude, pultrusion process, E-glass/polyester composite

${ }^{1}$ Department of Polymer Engineering, Faculty of Chemical Engineering, Shiraz branch, Islamic Azad University, Shiraz, Fars, Iran

*Corresponding author, e-mail: haghighi@iaushiraz.ac.ir

\section{Introduction}

In polymer composites, reinforcing fibers are placed among polymeric matrix. After curing, fibers tightly stay in their place. Fiber direction is an important parameter in determination the strength and elastic modulus of composite. For example if stress is applied in the direction of fibers, such as Fig. 1, since fiber has higher modulus in compare with polymeric matrix, most of the stress is tolerated by the fiber and tensile strength and modulus of composite will increase in compare with non-reinforcement matrix. However if stress is applied in transverse direction toward fibers direction, concentration of stress and strain in the interface of both fiber and matrix cause to decrease tensile strength of composite in transverse direction, thus composite tensile strength will be even lower than pure matrix and (lead to) composite which fails at lower strains [1-3].

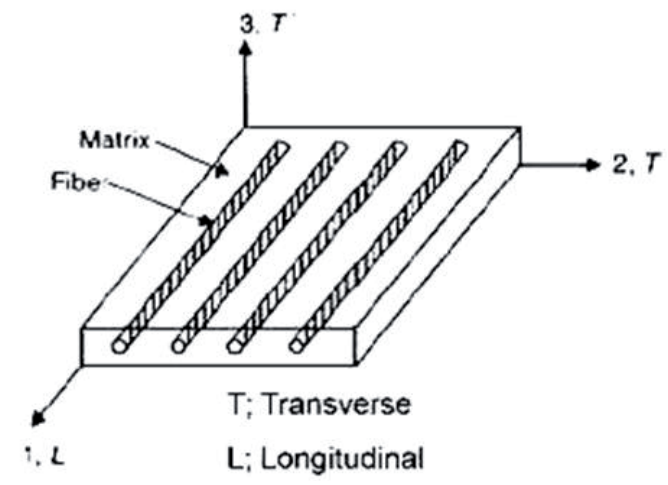

Fig. 1 One layer composite

Pultrusion process is a continuous process, which is used for producing continuous composite profiles with high speed. UD fibers have highest reinforcing among other shapes of fibers due to their high L/D ratio. UD fibers are mostly used in this process and highest volume proportion of composites is composed of these fibers [1]. So these processes result in products with high modulus and strength in longitudinal direction. On the other hand, since during the pultrusion process UD fibers cannot be fed in different angles in order to reinforce the product in transverse direction, use of other kinds of reinforcements 
Table 1 Process conditions for samples

\begin{tabular}{lccccc}
\hline Sample & $\begin{array}{c}\text { Fiber Volume Fraction } \\
\text { Vf }(\%)\end{array}$ & $\begin{array}{c}\text { Fiber Angle } \\
(\text { Degree })\end{array}$ & $\begin{array}{c}\text { Middle Mold } \\
\text { Temp. }\left({ }^{\circ} \mathrm{C}\right)\end{array}$ & $\begin{array}{c}\text { Enterance Mold } \\
\text { Temp. }\left({ }^{\circ} \mathrm{C}\right)\end{array}$ & $\begin{array}{c}\text { Rotation } \\
\text { Frequency }(\mathrm{Hz})\end{array}$ \\
\hline P0 & $47 \%$ & 0 & 145 & 150 & 0 \\
P1 & $47 \%$ & 1 & 148 & 150 & 27 \\
P2 & $47 \%$ & 3 & 145 & 150 & 27 \\
P3 & $47 \%$ & 9 & 145 & 150 & 27 \\
\hline
\end{tabular}

such as woven Roving /Fabric or chopped strand mat is needed. These kinds of reinforcements are only useful if high volume fractions are used, such as $80 \%$ while in these volume fraction, composite properties will decrease significantly due to weakening of polymer matrix [2, 3]. As a result, pultrusion products cannot be used in applications in which transverse forces are applied to them. In this study we effort to improve properties in transverse direction with modifying the pultrusion process.

\section{Experimental}

\subsection{Materials}

The Materials which are used in this study were polyester resin, glass fibers and benzoyl peroxide. Polyester resin was unsaturated orthophtalic resin of Scott Bader commercially which named as Crystic 197M (F). Glass fiber was Roving E-glass WR6 grade with TEX $=2400$ from Camelyaf Co-Turkey and Benzoyl Peroxide moistened and stabilized with 25\% water commercially named PE0160 from Scharlau-Spain.

\subsection{Fabrication of pultruded composite rods}

Pultrusion process was used to produce rods. Normal pultrusion machines cannot feed UD Fibers with different angles into the process and to do so special designs should be considered. Therefore a novel process called as Rotational pultrusion [4] was developed. More information on this process is given in following paragraphs.

\subsection{Rotational pultrusion process for production of composite rods with different fiber angles}

In this process all parts are as same as pultrusion process, except for pulling unit. The process conditions are shows in Table 1.

It is worth mentioning, Because of the processing condition in rotational pultrusion process, the best form of profile which can produce UD Fibers with different angles, is circular area profile which called rod, and can not produce rectangular profile.

In brief, processing as follows: woven roving fiber is dipped into resin to be wetted (along with other fillers) and pull through a long hot die which heated in range of $145^{\circ} \mathrm{C}$ to $150^{\circ} \mathrm{C}$. Steel die (Hot mold) forms wet fibers as well as controlling resin to fiber ratios. Wet fibers after leaving the die and cooling, enter into the gap between two rollers for coating with rubber and rotating in counter direction to each other. Speed and gap distance between two rollers are adjustable in order to control tensile which applied to the fibers when they are pulling out of die, so that, their modulus could increase [4].

Pulling unit along with this rotation has another rotation in axis of longitude of product which has a significant effect on final properties of the product. Pulling unit consists of two rows of 3 rollers rotating in the axis of composite rod and forcing fibers to rotate around same axis and new complicated fiber configuration will be formed in polymer matrix, which causes higher properties such as elastic modulus and tensile strength especially when transverse forces are applied to the rod. An increase in transverse strength of rod is observed due to the out of axial direction of angular fibers.

The product of normal pultrusion process, which consist of the belt tension system and pulling unit, if forcing entered to the piece in the transvers direction, not only be effective in reinforce the transverse properties of rod, but also decrease the reinforcement in compare with pure matrix rod. It should be noted that by controlling the rotation speed of pulling unit around its axis, reinforcing properties of product could be adjusted, so that if higher transverse properties is required, rotation speed should be increased. Also if higher longitude strength is needed, lower rotation speed should be applied and if only longitude strength is required, rotation speed could be set to zero to reach longitude direction as simple pultrusion processes. Figure 2 is the display of pultrusion process constructed machine.

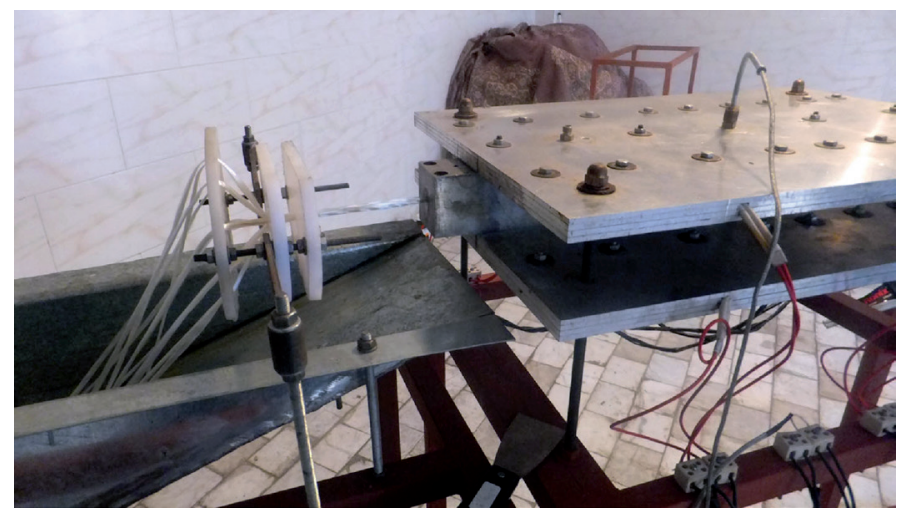

Fig. 2 Schematic of constructed machine for pultrusion process 


\subsection{Adjustment of rotational pultrusion machine for fabrication of samples}

In order to prepare samples, rotational pultrusion machine ASN 1000 [4] which is made by Iran was used. A box of fiber consists of 10 spool of UD fibers with TEX $=2400$ was used, from each spool, 1 strand of fiber was passed through out Teflon or HDPE holes to minimize abrasion and conducted to resin bath to be dipped in. Resin bath was filled with unsaturated polyester resin with $2 \%$ benzoyl peroxide initiator. After wetting fibers with resin, fibers were entered into an angle generator and then entered into two preformers, which were located in series. These preformers are form the initial shape of rod, regulate fibers and take out excess resin on fibers before entering into die. Initial product enters hot die and cure during passing through this die. Movement speed and curing time depends on temperature and process speed. Die was heated by two separate temperature controllers. One of these controllers adjusts die entrance temperature and the other one controls middle and the end part of the die. After complete curing in die, rod will cool down in a distance lag between die and enters next unit which is a unique pulling and rotating part. This system is controlled by two frequency inverters' starter. By changing frequency and input voltage in two electromotor of pulling-rotating system and controlling rotating speed, tensile force is applied on fiber and makes fibers to move from fiber box and cause rotation in fiber and finally angular fiber will be made on product. It should be noted that product is completely cooled before entering to the pulling unit and it has high stiffness.

Pulling unit consists of 6 rollers in 3 rows and each two set rotate in counter direction to each other by the movement of electromotor No.1 and by this rotation pull out composite rod from die. Roller rotating speed is controlled by inverter No.1 which can control production speed. This whole system is placed in a chamber which can rotate by another electromotor (Electromotor No.2) and its rotating speed is controlled by inverter No.2 and forms the final angular shape in fibers of product. By adjusting these electromotors samples with different fiber angles were produced. In this study 4 different samples with following process conditions as can be seen in Table 1 were used.

\subsection{Test procedure}

Three point beam bending test was performed by universal testing machine YLE (Germany) with $25 \mathrm{kN}$ load cell according to ASTM standard D-4476 and bending speed of $10 \mathrm{~mm} / \mathrm{min}$. Samples with 4 different fiber angles were prepared as rods of $5 \mathrm{~mm}$ diameter and standard length according to ASTM, bending force and deformation was calculated and modulus and bending strength was obtained. From each fiber angle, 5 samples were tested to assure the correctness of test results. From these five samples, 3 samples which had the best results were chosen to calculate modulus.
Bending modulus and strength calculated by following equations (Eq. (1), (2)):

$$
\begin{aligned}
& \mathrm{E}=4 \mathrm{FL}_{0}{ }^{3} / 3 \pi \mathrm{D}^{4} \mathrm{Y} \\
& \sigma_{\max }=8 \mathrm{FL}_{0} / \pi \mathrm{D}^{3}
\end{aligned}
$$

In which $\mathrm{F}$ is for force applied to samples, $\mathrm{D}$ is for sample diameter, $\mathrm{L}$ is for initial length of sample (distance between two fixtures) and $\mathrm{Y}$ is for deformation of sample.

\section{Results and discussion}

Since rod shape angular samples are less complicated for this rotational pultrusion process, this profile is chosen but due to its shape, testing transverse properties is difficult. Therefore in order to test transverse modulus of samples three point beam bending test was performed and bending strength was calculated. On the other hand bending is a combination of tensile and pressure test and since plastics and composites mostly have higher pressure modulus and strength than tensile modulus and strength. So bending properties can be representative of tensile strength. According to Fig. 3 and Fig. 4 it is obvious that by increasing fiber angle, both longitude modulus and strength are decreasing, while transverse direction modulus and strength are increasing. (Tsai-Hill and Tsai-Wu theory's are failure criteria in the composites, based on the formulation which is cited by them. These theory's are the two of orthotropic material failure criteria that they identify the type of failure in composite and shows the reasons of how the composite failure is happen such as, fiber failure, matrix failure or shear failure) [3].

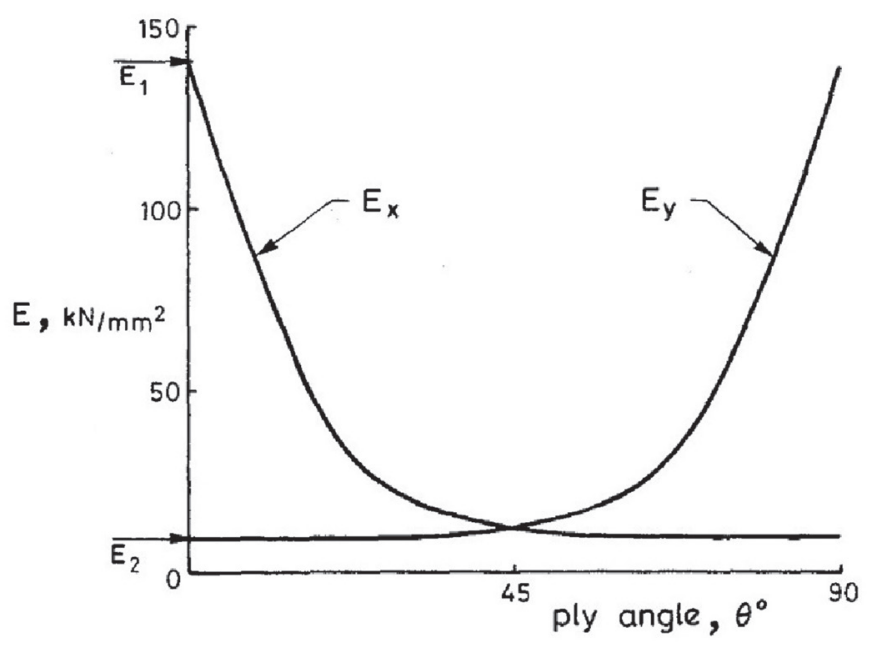

Fig. 3 Young's modulus variation with ply angle: unidirectional ply [3]

\subsection{Three point bending test results}

Data from 3 point bending test were reported as force $\left(\mathrm{N} / \mathrm{mm}^{2}\right)$ and deformation $(\mathrm{mm})$, by having distance between fixtures according to standards and having average diameter of samples in Eq. (1) and (2) stress and strain values could be obtained and diagrams were plotted. For example Fig. 5 shows the bending test results for sample P3. It shows that all samples 




Fig. 4 Longitudinal tensile strength variation with ply angle: unidirectional ply [3]

Table 2 Average stress and modulus of samples P0 to P3

\begin{tabular}{lcccc}
\hline Sample & P0 & P1 & P2 & P3 \\
\hline $\begin{array}{l}\text { Average Strength } \\
(\mathrm{MPa})\end{array}$ & 1276.5 & 1183.9 & 1081.1 & 987.37 \\
$\begin{array}{l}\text { Average Modulus } \\
(\mathrm{MPa})\end{array}$ & 69005.8 & 70068.6 & 63174.8 & 62221.8 \\
\hline
\end{tabular}

have similar behaviours. Table 2 shows average stress and modulus of samples P0 to P3. Average data extractions from best and similar 3 samples instate of 5 samples. Table 2 shows that, with increase in fiber angle, both average strength and modulus are decreased. As a result, the transverse strength and modulus are going to be increased.

Figure 6 shows the change in bending strength with increase in fiber angle that is predicted as a logarithmic function. As can be seen in Fig. 6, with increasing in fiber angle to $90^{\circ}$ (degree), the bending strength of samples, approximately $1300 \mathrm{MPa}$, decrease and in angle equal $90^{\circ}$ reaching to the lowest quantity equal 100MPa.

Figure 7 shows the change in bending modulus with increase in fiber angle which is predicted as a logarithmic function. Also as can be seen in Fig. 7, we observed similarity change in average modulus with bending strength by increase in fiber angle and decreased it. It is approximately $70 \mathrm{GPa}$ in zero angle to $22 \mathrm{GPa}$ in $90^{\circ}$ one.

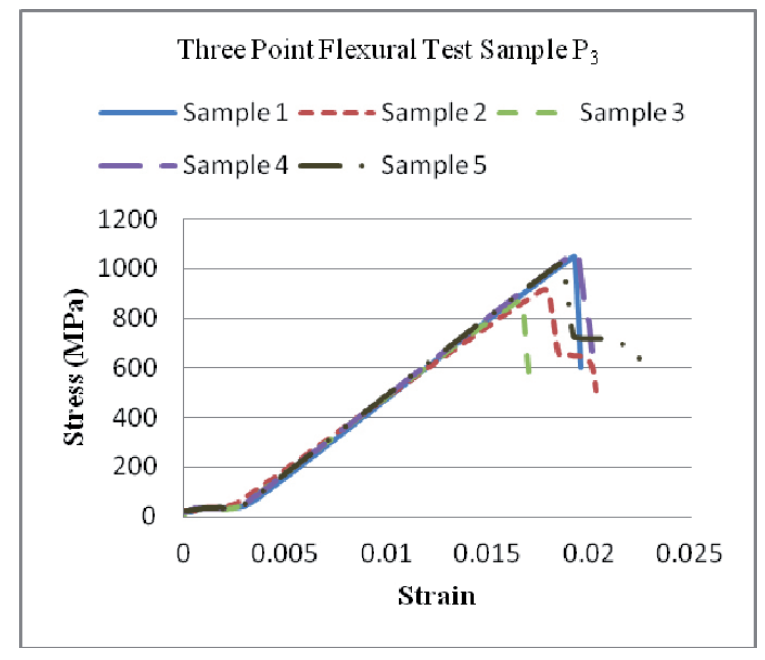

Fig. 5 Comparison of bending test results for P3 samples.

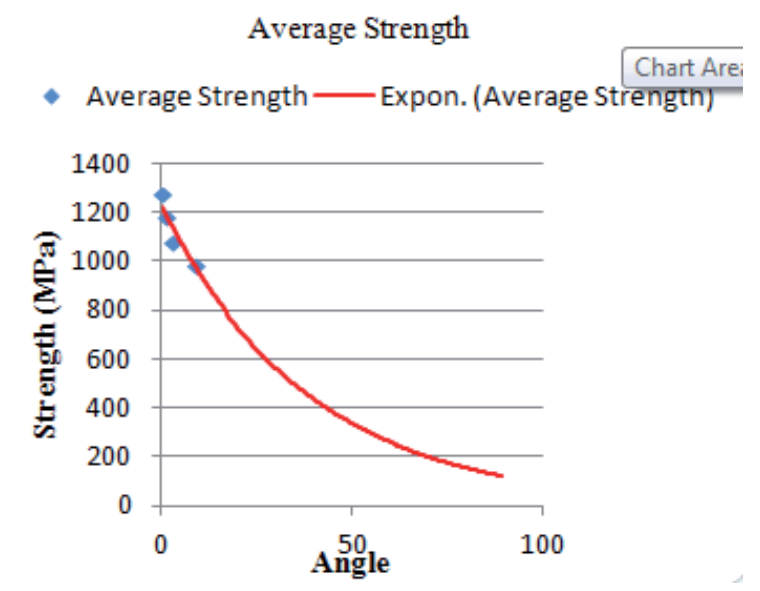

Fig. 6 Prediction of change in bending strength with increase in fiber angle

Average Modulus
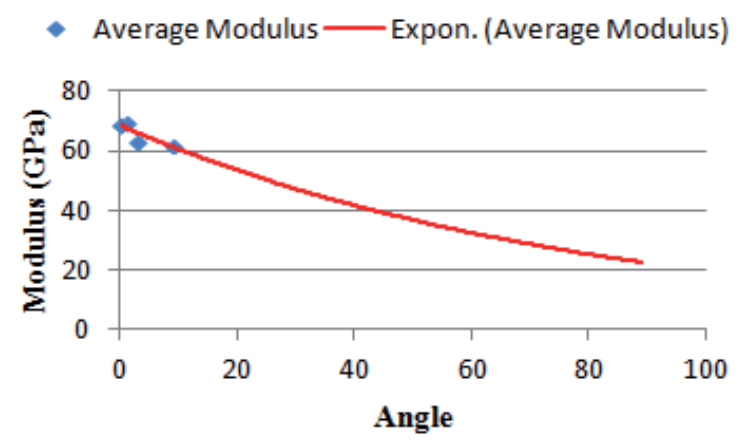

Fig. 7 Prediction of change in bending modulus with increase in fiber angle.

As it is obvious from above results, modulus and strength in longitudinal direction decrease with increasing fiber angle, and it is understandable from Fig. 3 and 4 that with decrease in longitudinal modulus and strength, these properties increase in transverse direction. 


\section{Conclusion}

Rotational pultrusion process is able to be fed by UD long fibers in different angles. Pultruded rod shape samples made from E-glass/polyester with different fiber angles and three point beam bending test were performed for these samples. As test results show, by increasing fiber angle according to its axial direction, both modulus and strength in transverse direction were increase.

\section{References}

[1] Beheshti, M. H, Rezadoust, A. M. "Reinforced Plastics (Composites)." Iranian Polymer and Petrochemical Institute. 2012.

[2] Starr, T. "Pultrusion for Engineers." Cambridge: Wood Head Publishing Ltd. 2000. DOI: 10.1533/9781855738881

[3] Datoo, M. H. "Mechanics of Fibrous Composites." Springer Netherlands, 1991. DOI: 10.1007/978-94-011-3670-9

[4] Jouyandeh, B. Rotational Pultrusion Process. 77861 Iran Patent: Office of Iranian Industrial Ownership Management. 2012 